\title{
Work in Progress: Retrospective Analysis on the Perspective of Instructors about Transitioning to Using Active-learning Strategies to Teach Mechanical Engineering Classes
}

\section{Mr. Sreenidhi Krishnamoorthy, University of California - Davis}

Mr. Sreenidhi Krishnamoorthy is a PhD candidate in Mechanical Engineering at the University of California - Davis. He works as a Graduate Student Researcher at the Western Cooling Efficiency Laboratory and as a Teaching Assistant Consultant at the Center for Educational Effectiveness, both on the UC Davis campus. As a Teaching Assistant Consultant, Sreenidhi focuses on improving undergraduate student learning by supporting the professional growth of Teaching Assistants. He has a Master of Science degree in mechanical engineering from the University of Cincinnati and a Bachelor of Technology degree from Indian Institute of Technology, Dhanbad - India. 


\title{
Work in Progress: Retrospective analysis on the perspective of instructors about transitioning to using active-learning strategies to teach mechanical engineering classes
}

\begin{abstract}
:
According to previous research, active learning methods have been stressed several times as being very effective for a better learning experience in engineering classes. However, an efficient transition process to using those methods is equally important to achieve the desired results in colleges that currently use lectures as the primary mode of teaching. The planning process involved in such a transition and its effectiveness was investigated by using the mechanical engineering department in a leading R1 university as case-study, where a departmental policy of promoting active learning methods in undergraduate classes was newly implemented. Professors and teaching assistants instructing mechanical engineering courses in this college were interviewed to understand the steps they went through to transition to using more active methods of teaching. Data collected from instructors-of-record in 5 different sophomore and junior level courses revealed their readiness levels on using interactive methods to enhance student learning. In addition, the immediate challenges that the instructors face due to this shift to active learning has been investigated. Since many of these courses rely heavily on teaching assistants (TAs) to run the active learning components of the courses such as discussion sections, the communication between TAs and their instructors-of-record about the method of conducting these sessions was also studied through the interviews. This work-inprogress provides insights into the differences in levels of receptiveness to active learning instruction methods between the TAs and faculty members. Finally, some information that would have enabled both TAs and instructors to make a smoother shift to active learning practices has been pointed out, which will be useful to other schools planning for a similar shift in their instruction methods in the future.
\end{abstract}

\section{Introduction:}

In engineering classes, active learning strategies have been implemented fruitfully in a variety of ways depending on the subject being taught. Examples include the easier to implement ways such as discussion sections, pair programming [1], creation of exam study-sheets [2] or slightly more challenging to implement but 
very productive ways such as use of a game software $[3,4]$ or use of a $3 \mathrm{D}$ image to teach P-V-T diagrams in thermodynamics [5]. One theme that is common to all the active learning strategies is that they work best when a sense of fun and excitement is induced in the learning process and students learn without realizing that they are actually "learning". Additionally, these strategies lead to learning results that are well beyond those obtained in traditional methods as published literature on interactive-engagement methods reveal [6, 7]. Inspite of these benefits, an engineering classroom where students learn through active-learning methods is still a fairly new concept for many instructors, as a result of which its implementation continues to be a challenge in many universities, especially R1 universities where there is a higher emphasis on faculty to focus on their research goals.

When compared to the amount of literature available on the benefits of active learning and the innovative methods to implement them, discussions about the challenges associated with transitioning to those methods and possible solutions to those obstacles are less prevalent. The availability of such information can equip colleges/departments trying to adopt these interactive teaching/learning models with pre-requisite information necessary to make the transition simpler. One issue with the introduction of a new teaching model across several courses without fully understanding their implementation is that faculty, especially those who are not exposed to the proposed new practices, might use the new methods inappropriately [8]. Even if the faculty have received exposure or have a general understanding of interactive methods in teaching, barriers may arise in the form of certain situational characteristics that ultimately prevent the use of research-based instructional strategies [9]. A smooth transition to a new course model that involves active-learning component hence requires a thorough understanding of the methods that instructors would be using, and receptiveness to actually implement them in their classes. The problem gets compounded in a teaching model that involves distinct passive and active components (such as separate times for lecture versus laboratory) and the two components are handled by different instructors, because the responsible individuals need to be in agreement regarding both the teaching methods as well as in sync on the content that they teach. A good example of this situation is seen in several R1 universities, where there is a general practice to hire Teaching Assistants to cover laboratory sessions, lead recitation/discussion sessions and help students with course projects in engineering courses [10]. Communication between teaching staff becomes a crucial aspect in the success of the change model here.

The current research work is an attempt to retrospectively analyze whether the transition process to an active-learning environment for certain Mechanical Engineering courses in a leading R1 university was satisfactory. The active component introduced was "Discussion Sections", and was brought about as a new policy in the Mechanical Engineering department of that university, whose name is being omitted from this paper considering the nature of the results. The positive and negative impacts that the preparation levels of instructors had in the way the Discussion Sections was implemented are described, and can be used by other universities who may be planning for similar transitions. 


\section{Research Questions:}

This work attempts to investigate the impacts of introducing mandatory discussion sections for five upper-division courses in Mechanical Engineering on the faculty and students concerned. The five courses in question are Dynamics, Fluid Mechanics, Thermodynamics, Heat Transfer and Experimental methods in Thermo-Fluids. The time allotted for discussion sections were distinct from and in addition to the time allotted to lectures (and laboratory sessions where applicable). The reasons for introducing the Discussion Sections are presented in the next section. In addition this work is an effort to address the following research questions:

1. Is the concept of active learning adequately understood (even in a very basic way) and well-received by faculty members of R1 universities?

2. What are some challenges in the transition process to a more active teaching/learning method, especially those not already known through previous research? What are some possible solutions to these challenges?

3. Are some instructors (both TAs and faculty members) receptive to change than others? What causes the difference in receptiveness?

4. What preparations do the students have to make in order to benefit from a course structure that involves distinct passive and active components?

In answering the first question, it is assumed that the results observed at the university where this study was conducted can be generalizable to all (or most) R1 universities. A sure way to validate this assumption would be to conduct similar studies at multiple R1 universities and analyze the assimilated results, however that is beyond the scope of this paper. Also, being a work-inprogress, the last question has not been addressed in this paper and will be explored in future research work.

\section{Research Methodology:}

Background information regarding the reasons for introduction of discussion sections for the five new courses were obtained from the department faculty committee. For Dynamics, Fluid Mechanics, and Thermodynamics courses, large enrollment was the primary reason for introduction of the discussion sections. It was agreed upon by the faculty committee that students should be given the opportunity to interact with the instructor of the courses in smaller groups, to enhance engagement with the learning material. For the remaining two courses, high student workload and the lack of time to cover the syllabus in the allotted time steered the decision towards adding another credit unit for that those courses, and this was accomplished by introducing discussion sections. Details about the courses such as number of students, number of Teaching Assistants, and the duration of discussion section are indicated in Table 1.

Table 1: Details about the enrollment, TAs, and time allotted for discussion sections in the courses surveyed. 


\begin{tabular}{|l|l|l|l|l|}
\hline Course & Enrollment & $\begin{array}{l}\text { Number of } \\
\text { Teaching } \\
\text { Assistants }\end{array}$ & $\begin{array}{l}\text { Number of hours } \\
\text { allotted for } \\
\text { discussion section }\end{array}$ & $\begin{array}{l}\text { Number of hours } \\
\text { allotted for } \\
\text { lectures/laboratory }\end{array}$ \\
\hline Thermodynamics & 40 & 1 & 1.5 & 4 \\
\hline Fluid Mechanics & 90 & 3 & 1 & 4.5 \\
\hline Dynamics & 50 & 1 & 0.5 & 2.5 \\
\hline Heat Transfer & 105 & 3 & 0.5 & 2.5 \\
\hline $\begin{array}{l}\text { Experimental Methods in } \\
\text { Thermo-Fluids }\end{array}$ & 60 & 1 & 1 & 4.5 \\
\hline
\end{tabular}

With the understanding of the above background information, instructors (including TAs) from these five courses were interviewed to obtain answers to the research questions above. The following questions were asked of the interviewees.

1. How are discussion sections handled? What methods are used?

2. What preparations did the instructors make to handle the transition to discussion sections?

3. Are the discussion sections handled by the TAs or the instructor? What guidance is provided to the TAs to help with leading discussion sections?

4. Would the instructors/TAs do anything different in the discussion sections during the next offering of this course?

Interviewees were given a confidentiality agreement letter stating that their responses will remain strictly anonymous and will only be used for the purpose of this research study.

While this work is an attempt to answer specific research questions mentioned earlier, the participants involved in this study, the author, and the readers will all be obviously interested in whether the introduction of the discussion sections increased student learning. In order to make a fair assessment of student learning by not basing the results solely on instructors' views, the assessment of student learning with the new course format was determined through data collection of course grades and the online course feedback submitted by students at the end of the courses. The outcome of introducing discussion sections in terms of increased student learning is discussed in a limited way as part of this study's results. A broader analysis of student learning will be part of continued work for this project.

\section{Preliminary Results :}

Based on the responses collected from the interview, the implementation methods and the outcome of discussion sections in terms of improvements in student learning are presented below.

1. Methods used in discussion sections and implementation

The different methods used in newly introduced discussion sections for the five courses ranged from having an open floor for students to ask clarifying questions to instructors, problem solving 
in small groups, and problem solving as in a traditional lecture setting (with the entire time dedicated to only solving numerical problems). Interestingly, only one out of the five courses surveyed for this study had students working in groups during discussion sections, otherwise the students worked individually. This was for the Thermodynamics course, where the TA conducted the discussion sections under the general direction but minimal supervision of the instructor. The TA would divide the class into groups of no more than 4 students, and have each group work individually on numerical problems while continuously encouraging them to discuss the solution methodology within their groups. If however it appeared that multiple groups were unable to figure out the solution to a problem, the TA would bring the whole class back as a group and explain the underlying concepts. Both the TA and the instructor for this course reinstated during the interview that having students work in groups would create more opportunities for interaction between students, and thus make the classroom more engaging through peer-to-peer learning as opposed to a situation where the instructor simply works out problems on the white-board. Furthermore, the instructor was very supportive of his TA trying innovative teaching methods that are not very common or frequently used in the department courses as long as the goal was to improve student engagement. For this class of 40 students, the one and a half hour long, once-a-week discussion section was divided into 2 equal groups and occurred in back-to back sessions following a half hour break after the lecture. The second discussion session experienced a lower level of participation both in terms of attendance and attentiveness despite the TA having just led a similar session, which the TA attributed to the time of day during which the session was scheduled ( $7 \mathrm{pm}$ in the evening). As a whole, this class appeared to have very engaged discussion sections during the entire duration of the course.

The Fluid Mechanics class had an enrollment of ninety students and the class was divided into four discussion sections. The implementation method here was a "reduced" version of what was experienced in the Thermodynamics class. The instructor-of-record picked numerical problems and handed them over to the Teaching Assistants. The TAs spent the first ten minutes reviewing the lecture material and then provided time to students to individually work on each numerical problems before walking them through the solution. Each TA would conduct one discussion section per week. There was an average attendance of 5 to 15 students per section, with lower attendance again being experienced when the discussion sections were held in evening hours.

Two of the three TAs for this course stated that it was difficult to get students engaged during the discussion sections because of the structure that they used for conducting the discussions. The TAs had to walk through three numerical problems following a quick overview of the concepts used in those problems, all in one hour. Obviously the structure was set by the instructor and the TAs had little control over it, however the TAs felt that if they were given the freedom to design the lesson plan, they would make it less about them solving problems for the students. One of the TAs said he would instead make the discussion section an open brainstorming session where students can freely express practical project ideas that can emerge based on the content being taught.

The remaining three courses surprisingly had very low level of active learning, if any, despite the introduction of dedicated discussion sections. For e.g., the instructor for the course 
"Experimental methods in Thermo-Fluids" primarily used the discussion sections to answer any clarifying questions from students, and he believed this to be this primary purpose of discussion sections. The instructor confirmed that for this 60 student classroom, he simply proceeded with lecturing the rest of the material during the discussion section if the students didn't ask any questions.

Similarly, for the "Dynamics" course, the instructor simply used the discussion hour as additional time for lecture. This instructor's view was that several students in this 50-student class did not have the prerequisite background and there was no time to elaborate on such information during the regular lecture hours. As a result, he would use this time to lecture on prerequisite material. In addition, the instructor admitted to being a "conventional" teacher who was brought up in his student days as well as the major portion of his faculty days in the traditional lecture style of teaching and learning. However, the instructor emphasized that he would always encourage the students to ask questions during the lecture which he believed was a major component of active learning, and thus he believed that he was "integrating active learning into his lectures". The TAs for this course didn't have much freedom to try their own innovative methods either. During the very rare occasions they got to teach, they would simply lecture as a substitute for the instructor.

For the final course "Heat Transfer", the instructor was not even aware until the interview that the course had a "discussion section"; i.e. the instructor was under the assumption that the times listed on the course catalogue for this class were all lecture hours. Obviously, this professor acknowledged that he did nothing different in the class during the time meant for discussion section than what he did during the lectures. The TAs for this class said they never got a chance to teach as the professor mainly had them perform grading work and hold office hours.

\section{Impact of introducing discussion sections on student learning}

As described earlier, learning outcomes of discussion section were measured primarily through course grades and online student feedback for the courses. For the analysis of course grades, the average grade point for all students in the class was obtained for each of the 5 courses and was compared with the average grade point for the most recent instance of the same course taught by the same instructor-of-record (with or without different TAs) prior to introduction of discussion sections. The instructor-of-record for "Heat Transfer" class hadn't taught an offering of this course prior to the introduction of discussion sections, and hence the grade point data without discussion sections was not available for this course. The comparison of course grades is shown in Figure 1, from which it can be inferred that introducing discussion sections didn't have a major influence on grade points. The grade point data shows a variation of $5 \%$ or less in the average grade point with and without discussion sections. At best, this difference falls in the noise levels of comparison of the data. Only two courses, namely, Fluid Mechanics and Experimental methods in Thermo-Fluids showed a slight increase in the grade points. 


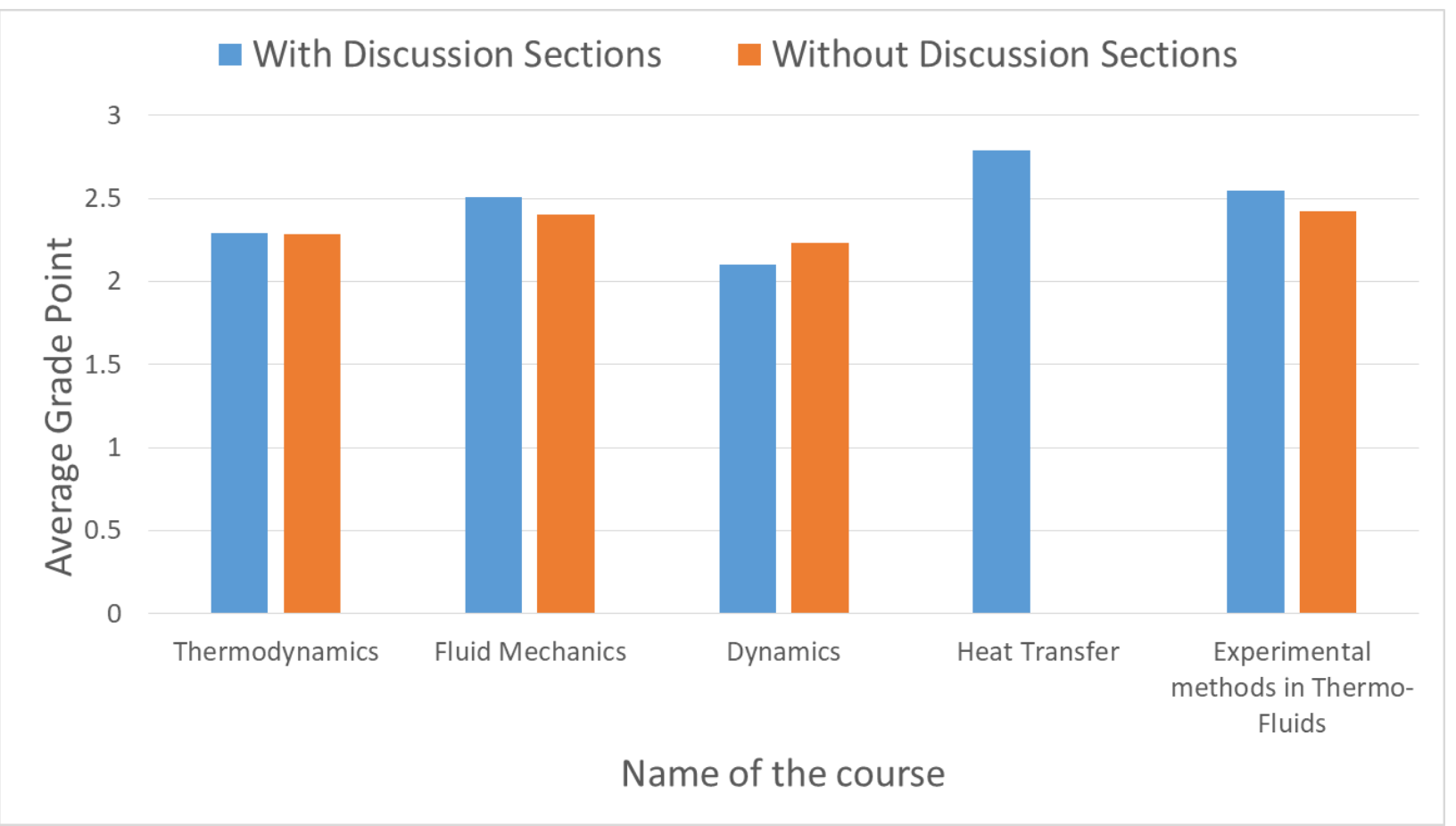

Figure 1: Comparison of average grade-points for different courses with and without the "discussion section" component. Note: Grade point data was unavailable for "Heat Transfer" class without discussion sections.

While evaluating student learning through course evaluations, multiple mentions were seen in the course evaluations filled out by students of the Thermodynamics class that they found the discussion sections very useful. One of them said "I learn best through group work and the discussion sections are most suited for me." Another comment was "Doing practice problems in discussion section should be emphasized the most." A similar comment was also seen in the fluid mechanics course evaluations, however the comment also stressed that "only concepts are covered during lectures", through which it can be understood that the discussion sections were very much necessary. Unfortunately the student feedback from other three classes had very little mention of discussion sections. This is understandable, given that the instructors used the allotted time primarily as additional time for lectures. For these courses it can only be understood through further investigation whether the students preferred a different method of learning other than the lecture-style that they experienced, since the online feedback wasn't tailored to answer this question.

\section{Discussion:}

The findings about the methods used in discussion section lead us to conclude that there was no common pattern in the way discussion sections were held for the 5 courses surveyed. Every instructor used his/her own preferred method to use the additional time allocated. With at least 
one instructor being unaware of having a discussion section for his class, the findings also suggest that the instructors were inadequately prepared by the department to transition to the courses with discussion sections. Most of the instructors only had a crude understanding of engaging classrooms through active methods. The department made the first step in moving towards engaged classrooms by adding the discussion sections on the course catalogues, but to achieve desired results the faculty and TAs responsible for these courses appear to be needing training on the purpose and methodology of adopting active learning methods. In addition, not every instructor appears to be in agreement with moving away from "conventional" teaching styles because of the way their educational backgrounds have evolved. Special consultation sessions could be provided to those instructors to overcome their hesitation and create a positive mindset in them on the implementation of active learning strategies.

One way to execute the above-mentioned fixes may be to involve the university's teaching and learning center, using their expertise in evidence-based learning methods to specifically tailor to the Mechanical Engineering department's student learning goals. For example, it was found during the interview process that more than one instructor encouraged the process of student interaction with them through asking questions about the course content that students couldn't understand during the lecture. This process could be formalized and made very efficient through implementing the "Muddiest point" technique, as was used in the engineering classes of another leading R1 institution [11], which an educational specialist would be more adept at to train the instructors.

This views of the TAs for the Thermodynamics and Fluid Mechanics courses suggest that TAs have creative ideas about leading a class in a non-conventional fashion, i.e. they seem to be more receptive to the idea of active learning. All TAs were relatively young compared to the instructor-of-record for their courses, which also implies that young instructors may have a much more positive/creative mindset about engaging students. It was also learnt as part of the interviews conducted that the TA for the Thermodynamics class had received formal training on student-centered-instruction methods through attending a teaching workshop series. As a result, he was very much aware of the importance of engaging students in a classroom and various methods to do so.

Finally, it can be said in terms of learning outcomes that the courses with and without discussion sections were not very different in terms of the overall grade of the course. In particular, the Thermodynamics class that showed the maximum characteristics of active learning among all the five courses showed no variation in GPA, and two other classes showed only a slight increase. Given that students in these courses felt the discussion sections worked well for their engagement with the material, it could perhaps be that a summative evaluation isn't robust enough to parse out the impact on learning and instead, formative assessment during the course should be conducted in the future to assess the impact of active learning strategies more deeply. 


\section{Conclusion and Directions for Future work:}

The change model adopted in the implementation of active learning modes in the course structures of five Mechanical Engineering classes in an R1 university was studied retrospectively. The history behind the reasons for the introduction of dedicated discussion sections, the methods used in those discussion sections, and the readiness levels of faculty and teaching assistants to transition to the new format was investigated. The lessons learnt through this study, in particular the importance and methods of adequately preparing the faculty for introducing discussion sections or other active learning methods will be useful for engineering programs who plan to make a similar transition in their teaching methods. Additionally, a reasonable analysis of student grades with and without discussion sections has been performed, but in the light of failure of proper education of faculty about the purpose of discussion section, the authors have decided to conduct that analysis again after proper education of faculty on active-learning methods. Such an analysis is expected to reveal a sharper improvement in student learning outcomes, and hence will further highlight the important of faculty preparation in active learning methods. Some other limitations of the research performed include insufficient investigation on the preparation level of students for the discussion sections and the inability to investigate instructor gender as a factor that contributes to different receptiveness levels towards using active learning strategies. These topics will be explored in detail prior to the completion of this study.

\section{References:}

1. Bevan, J., Werner, L., and McDowell, C. (2002). "Guidelines for the Use of Pair Programming in a Freshman Programming Class." Fifteenth Conference on Software Engineering Education and Training, Covington, KY, USA.

2. Sharp, J.E., Harb, J.N., and Terry, R.E. (1997). "Combining Kolb Learning Styles and Writing to Learn in Engineering Classes." Journal of Engineering Education, (86(2)), p. 93-101.

3. Overmars, M. (2004). "Teaching computer science through game design." Computer, 37(4), p. 81-83.

4. Ebner, M., and Holzinger, A. (2007). "Successful implementation of user-centered game based learning in higher education: An example from civil engineering." Computers \& education, 49(3), p.873-890.

5. Siow, Y. (2015). "Incorporating Active Learning of Complex Shapes in STEM Courses Paper" 122nd ASEE Annual Conference \& Exposition, Seattle, Washington.

6. Hake, R. R. (1998). "Interactive-engagement versus traditional methods: A six-thousandstudent survey of mechanics test data for introductory physics courses." American journal of Physics, 66(1), p. 64-74. 
7. Freeman, S., Eddy, S. L., McDonough, M., Smith, M. K., Okoroafor, N., Jordt, H., and Wenderoth, M. P. (2014). "Active learning increases student performance in science, engineering, and mathematics." Proceedings of the National Academy of Sciences of the United States of America, 111(23), p. 8410-8415.

8. Beach, A. L., Henderson, C., and Finkelstein, N. (2012). "Facilitating change in undergraduate STEM education.” Change: The Magazine of Higher Learning, 44(6), p. $52-59$.

9. Henderson, C., and Dancy, M. (2007). "Barriers to the use of research-based instructional strategies: The influence of both individual and situational characteristics." Physical Review Special Topics: Physics Education Research, 3(2), 020102.

10. Plakans, B. S. (1997). 'Undergraduates' experiences with and attitudes toward international teaching assistants." TESOL quarterly, 31(1), p. 95-119.

11. Hall, S. R., Waitz, I., Brodeur, D. R., Soderholm, D. H., and Nasr, R. (2002). “Adoption of Active Learning in a Lecture-based Engineering Class." 32nd ASEE/IEEE Frontiers in Education Conference, Boston, MA. 